\title{
Welfare state and the age distribution of public consumption and public transfers in the EU countries
}

\author{
Agnieszka Chłoń-Domińczak ${ }^{1, *}$, Anita Abramowska-Kmon ${ }^{1}$, \\ Irena E. Kotowska ${ }^{1}$, Wojciech Latkowski ${ }^{1}$ and Pawet Strzelecki ${ }^{1}$
}

\section{Abstract}

The article extends the discussion of the welfare state in the literature by presenting a quantitative assessment of the age distribution of public resources. It investigates the differences in the distribution of public transfers between age groups in different European welfare state regimes using the National Transfer Accounts approach. There are two groups of countries that stand out in terms of the age patterns of their public transfers: three Scandinavian countries and Luxembourg have relatively high transfer levels, particularly for the older age group; while some of the Central and Eastern European countries have relatively low transfer levels. In the other European countries, the age profiles of public transfers are close to the EU average. Total public expenditures and revenues in the two distinct groups are changing in response to population ageing: i.e. they are expanding in the Scandinavian countries, and they are contracting in the CEE countries. These developments may lead to the further divergence of these welfare regimes.

\section{Introduction}

Our aim in this article is to broaden the current discussion on welfare regimes in Europe by providing additional evidence on the similarities and the differences in public consumption and transfer levels from an intergenerational perspective across welfare regimes. We extend the analysis of welfare states typology based on the main macroeconomic approach that has been used in other studies (e.g. Schut et al. 2001; Powell and Barrientos 2004; Arcanjo 2011) by adding the generational

\footnotetext{
${ }^{1}$ Institute of Statistics and Demography, Warsaw School of Economics, Poland

${ }^{*}$ Correspondence to: Agnieszka Chłon-Domińczak, achlon@sgh.waw.pl
} 
dimension using National Transfer Accounts data. We are thus able to investigate how public transfers to different age groups vary by welfare state type.

The starting point for our analysis is the Esping-Andersen welfare state typology (Esping-Andersen 1990, 1999). In recent years, developments in European welfare states have been influenced by the impact of the Great Recession, which led to the deterioration of public finances, and, as a result, to the implementation of austerity measures that have affected social transfers. Another important development in these countries is population ageing, which has also triggered welfare system reforms. In addition, to address the existing and the emerging social challenges European countries face, we extend the analysis by covering not just developed economies, for which there is a substantial body of welfare state research; but the new EU member states, which first started developing their welfare states in the early 1990s after the transition to a market-based system.

Using the National Transfer Accounts (NTA) approach, we provide a quantitative assessment of the age distribution of public consumption of education, health, and other items in the EU countries; as well as of public transfer inflows and outflows by age groups. The NTA age profiles of public consumption serve as a tool for investigating how public consumption and public transfers are distributed across three age groups: young ( $0-19$ years old), working-age (20-64 years old), and senior (65 years old and older). The findings on public consumption and transfers by age groups are then used to identify distinct groups of countries by applying a cluster analysis, which enables us to determine whether the age distribution of transfers differs substantially across the welfare state types identified in the literature.

Our approach builds on the existing literature on welfare regimes and methods, and on the research areas covered by welfare analysis. We contribute to the debate on welfare state regimes in several ways. We use the combined macro and micro approach, while taking into account all public transfers and forms of consumption, including those for education and health, which are usually not covered in welfare regime classifications. We focus on the quantitative outcomes of welfare regimes, as measured by public inflows and outflows, which reflect the designs of the tax benefit systems in different welfare state regimes. Thus, we also account for decommodification and labour market outcomes.

Our focus in this paper is on redistribution that is related to age. As our interest is in exploring the generational aspects, we do not consider income redistribution. Esping-Andersen and Myles (2009) discussed how redistribution under three different types of welfare states affects income inequality. The authors demonstrated the differences between these welfare regimes by referring to empirical evidence from the cross-country comparisons of spending profiles at the macro level, while also examining the role of private welfare and social services, and the degree to which transfers are targeted. Finally, they suggested that research on the effects of redistribution on income inequalities under different welfare regimes should refer to demographic developments, especially those related to the population's age composition and family structures. In our study on the redistribution of public consumption and public transfers, we provide a different perspective on redistribution under different welfare state types by looking at differences in the 
age-related profiles of consumption and transfers. The main focus of our analysis is the distribution of public transfers by age, which explains the majority of public redistribution (see, for example, Gál and Medgyesi 2017).

Given the research objectives, we formulate the following hypotheses:

H1: In countries with a social democratic regime (with a developed welfare state), there are high public transfer levels for all age groups.

H2: In the majority of Eastern European countries, the welfare regime is still being developed, and public transfer and public consumption levels are still relatively low.

H3: The welfare models of countries are converging, especially in response to macroeconomic shocks and population ageing.

H4: In recent decades, and especially after the onset of the financial crisis, public expenditures and revenues, as well as social protection spending, evolved differently across countries depending on their welfare regime type.

The article starts with a brief discussion on the welfare state typologies developed in the literature. We then describe the NTA approach, as well as the data used. Next, we present our findings on levels of public consumption and public transfers in the intergenerational context. We then perform a cluster analysis to group countries by their patterns of public transfers and consumption for the young, prime-age, and senior generations. Finally, we analyse how the public expenditures in the clusters are linked to changes in the age structure of the population. We conclude with the verification of our four hypotheses.

\section{Typologies of welfare states}

There is a growing body of literature that focuses on the classification of developed countries by welfare regime. Scholars have used a range of approaches to classify countries into relatively homogenous groups. One of the most commonly cited approaches is the typology proposed by Esping-Andersen (1990), elaborated for democratic developed countries. His analysis of welfare regime types was based on de-commodification and social stratification, which are linked to different employment levels and patterns This approach resulted in the identification three types of welfare state: conservative, liberal, and social democratic. Esping-Andersen then clustered countries according to this typology.

The conservative welfare regime is characterised by a moderate level of decommodification. The social rights of individuals, and, consequently, most social benefits, are differentiated on the basis of class and status. The family is the main provider of care and support, and the state steps in when families are not able to fulfil their obligations to their members. In these societies, both employment and women's labour market participation rates are relatively low. This type of welfare regime was initially found in Italy, France, Germany, Austria, and Belgium.

In the liberal welfare state, levels of de-commodification and of market differentiation of welfare are low, while both employment and women's labour market 
participation rates are relatively high. The market is the main source of social benefits and services, and state support is provided only to those who cannot purchase such services on the market. The benefits provided by the state are, in general, mean-tested, and the eligibility requirements are strict. ${ }^{1}$ This type of welfare regime was said to characterise Australia, Canada, the United States, Switzerland, and Japan.

The social democratic type of welfare state is distinguished by its high level of de-commodification, universal benefits, and high degree of benefit equality. The employment rates are the highest among all the regime types, including for women. Based on the social democracy principles, which emphasise the importance of social equality and economic redistribution, the state provides a wide range of social benefits aimed at enhancing universal solidarity. This cluster was originally comprised of the following countries: Denmark, Finland, Norway, Sweden, and the Netherlands.

In reaction to criticism of the concept of three "worlds of welfare", and especially the charge that it neglected the gender dimension (i.e. Lewis and Ostner 1994; Korpi and Palme 1998), Esping-Andersen (1999) revised his approach. The conceptual framework was extended by placing more emphasis on labour market regulations, and on the family and household economy. In particular, more attention was given to the increase in women's labour force participation and its effects on the family, and to family policy measures. This new approach was based on the same classification system as the primary classification system of Esping-Andersen (1990). Thus, while the three types of welfare states were maintained, the descriptions of these types were considerably enriched with more insights into labour markets structures, women's employment patterns, and family social rights (familialist versus nonfamilialist countries). ${ }^{2}$ However, this extended typology was still criticised. It was, for example, pointed out that the Mediterranean countries were incorrectly identified as immature continental welfare states, while the Antipodean states were erroneously assigned to the liberal group (i.e. Arts and Gelissen 2002; Arcanjo 2006). Moreover, the way gender was incorporated into the typology was still subject to criticism (Daly and Lewis 2000; Leira 2002). Consequently, alternative classifications of welfare states have been proposed, including approaches that focus on the Mediterranean countries and the Central and Eastern European countries, and approaches that concentrate on different aspects of social policy (e.g. social services and care transfers, and their gender-related aspects) (i.e. Ferrara 1997; Arts and Gelissen 2002; Powell and Barrientos 2004; Arcanjo 2006, 2011; Fenger 2007, Cerami and Vanhuysse 2009; Kammer et al. 2012).

Generally, the typology of welfare regimes refers to the institutional design of welfare policies. However, efforts to classify countries according to their real social

\footnotetext{
1 For example, the United States is an exception.

2 Austria, Germany, Italy, Japan, the Netherlands, Portugal, Spain (and, less so, Belgium and France) were included the familialist group; while Australia, Canada, Denmark, Finland, New Zealand, Norway, Sweden, the UK, and the United States constituted the non-familialist group (Esping-Andersen 1999: 86).
} 
policy outcomes tend to be based on different approaches, statistical techniques, and data (mostly macro-data). Thus, such classification efforts generate different results, which are, inter alia, manifested in differences in the number of clusters, and in the countries that make up these clusters. Some scholars have also reflected on the difference between "ideal" and "real" welfare states. As Kammer et al. (2012) pointed out, a majority of studies on this topic have extended or criticised the categorisation of welfare regimes on qualitative grounds. Moreover, the use of macro-data to test empirically proposed typologies does not allow researchers to capture the effective distribution or redistribution of resources across households or age groups. Hence, the use of micro-data is recommended. Kammer et al. (2012) have extended the current literature using micro-data from the EU-SILC. Moreover, the outcomes of their micro-data analyses on the distributional effects of different welfare regimes are mostly in line with Esping-Andersen's typology.

Another aspect that tends to be neglected in these studies is the intergenerational effects of different welfare regimes. Chauvel and Schroder (2014) looked at intergenerational inequalities across existing welfare regimes by applying the ageperiod-cohort model to micro-data from the Luxembourg Income Study Database (LIS 2012, years 1985-2005). Intergenerational inequalities - expressed in terms of disposable income, youth unemployment, and investments in younger generations were found between the 1945-1955 birth cohorts and other cohorts. The biggest inequalities were detected in conservative welfare regimes.

There are also approaches to classifying welfare regimes that refer to the intergenerational exchange of care (Saraceno and Keck 2010) and to welfare services (Stoy 2014). The latter approach extended Esping-Andersen's clusters (1999) by including information on health care and social care, and by defining a new cluster made up of Eastern and Southern countries.

Our approach attempts to provide a new clustering of countries that takes into account both the institutional framework and the patterns of transfers and public consumption across generations, while making use of both macro- and micro-data. In addition to contributing knowledge about how different welfare regimes shape the intergenerational distribution of transfers and public consumption, we aim to explore the question of whether the welfare measures implemented over two last decades - and especially those imposed following the 2008 financial crisis - have resulted in the different welfare regimes diverging or converging (in terms of their distributional effects). As Powell and Barrientos (2004) concluded in their analysis of the development of welfare regimes over time, welfare states are changing in response to macroeconomic shocks; and these changes are, in turn, causing welfare regime typologies to evolve.

\section{Analytical approach and data sources}

In our analysis, we aim to provide a quantitative assessment of welfare state typologies based on the age profiles of public consumption and public transfers. 
Figure 1:

Research design: macro-level, micro-level, and National Transfer Accounts approaches to analysing welfare regimes

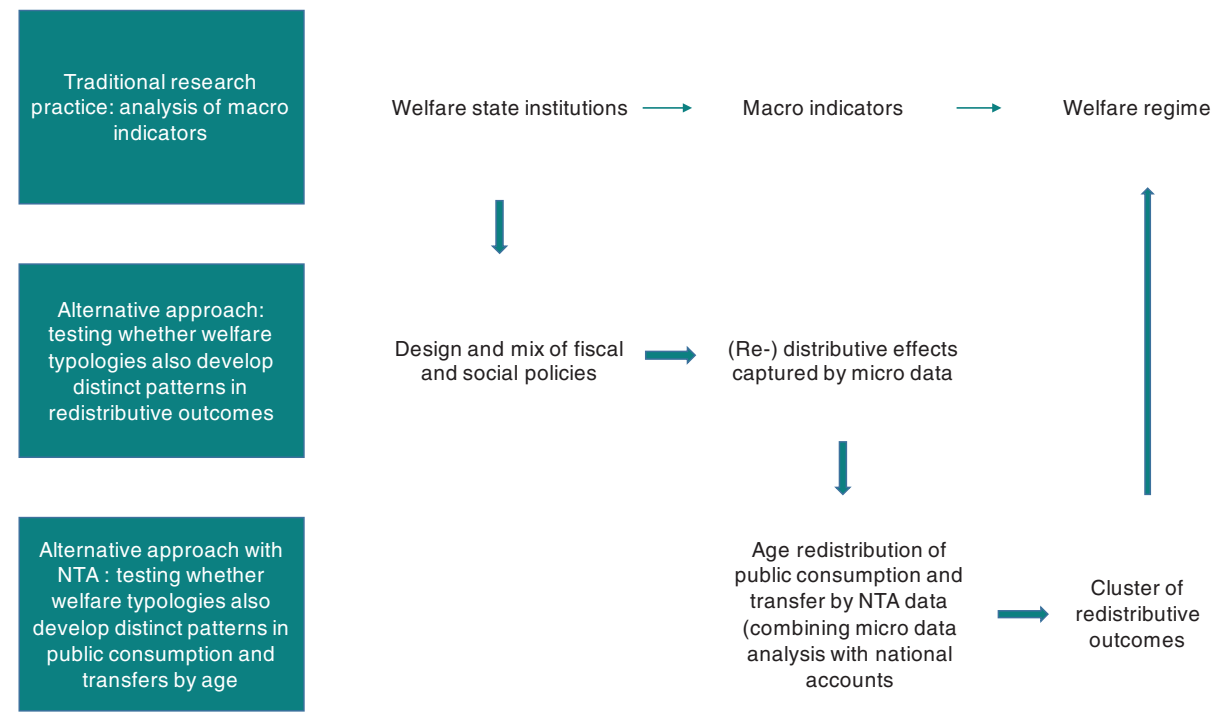

Source: Own modification of Kammer et al. (2012).

To that end, we use the National Transfer Accounts (NTA) approach proposed by Lee and Mason (see, for example, Lee and Mason (2011a,b); Lee (2013)). The application of the NTA combines the macroeconomic approach, which is traditionally used in studies on welfare regimes; with the microeconomic approach, which allows us to determine the direction of public transfers to different age groups. We examine public transfers, including public consumption (e.g. health and education services) by age, and seek to identify the distributional outcomes of the institutions that comprise the welfare state regimes of EU countries.

Our analytical approach extends the approach proposed by Kammer et al. (2012), who added the assessment of the patterns of redistributive outcomes to the analysis of welfare state institutions and macroeconomic indicators. We further extend this approach in our analysis by taking into account the age patterns of the distribution of public transfers, as shown in Figure 1.

In the NTA approach, at each age $(x)$, individuals have a certain level of consumption. Those who are economically active finance their consumption from their labour income $\left(Y^{l}\right)$. If their labour income is not sufficient, a life-cycle deficit $(L C D)$ appears. The LCD is financed from transfers (public and private), which are the difference between transfers received and paid $\left(\tau^{+}(x)-\tau^{-}(x)\right)$ by age, as well as the reallocation of resources $\left(Y^{A}(x)-S(x)\right)$. This is expressed by the following 
equation:

$$
L C D(x)=C(x)-Y^{l}(x)=\tau^{+}(x)-\tau^{-}(x)+Y^{A}(x)-S(x),
$$

where:

$$
\begin{array}{ll}
L C D(x) & \text { - life-cycle deficit; } \\
C(x) & \text { - consumption, comprising public and private consumption that is } \\
& \quad \text { used for health care, education, and other purposes; } \\
Y^{l}(x) & \text { - labour income; } \\
\tau^{+}(x) & \text { - transfers received (public and private); } \\
\tau^{-}(x) & \text { - transfers paid (public or private); } \\
Y^{A}(x) & \text { - income from assets; and } \\
S(x) & \text { - savings. }
\end{array}
$$

Members of the working-age generation earn income, which is used to finance their consumption, but also to generate transfers that are used to finance the consumption of both children and the senior generation; either directly through private transfers, or indirectly through public transfers. The public transfer and public consumption levels are determined to a large extent by the existing welfare state institutions.

We take into account the age profiles of public transfer inflows and outflows according to the NTA manual (UN 2013: 113). Public transfer inflows refer to flows received by the beneficiaries of all public programs, broadly measured to include cash transfers and all in-kind transfers considered to be equivalent to public consumption. In-kind transfers include both public goods and services that can be readily assigned to individuals; e.g. public education (from pre-school to higher education) or publicly-provided health care; and collective goods and services, including government administration, public safety, and national defence. Public transfer outflows are defined as the current flows from each age group (or the rest of the world) that fund public transfer inflows. Public transfer outflows are funded by taxes, social contributions, and grants to the government. If these funding sources are insufficient, a balancing item, or the transfer deficit, funds the shortfall. If taxes, social contributions, and grants exceed transfer inflows, a transfer surplus is generated. By definition, transfer inflows and outflows must be equal for public transfers to occur, both in general and for each type of public program.

Our analysis focuses on public transfers, which include both in-kind transfers, which are equivalent to public consumption, and cash transfers. In the welfare state regimes, cash transfers are important for the purposes of de-commodification. We also separately investigate public consumption of education and health services, which are mainly used by the younger and the senior generations, and which vary between welfare regimes.

We use the European NTA database, which was developed within the project "Ageing Europe: An application of National Transfer Accounts (NTA) for explaining and projecting trends in public finances (AGENTA) financed under the 7th Framework Programme" (Istenič et al. 2017). The NTA database was prepared through the extensive calculation of data from existing administrative, demographic, 
and survey data, including harmonised Eurostat data from the income (EU-SILC) and the household budget surveys for 2010. The harmonisation of these data ensures that the estimated age profiles are comparable, and reflect differences in the public institutions and welfare regimes of countries.

The analysis covers $24 \mathrm{EU}$ countries, including the new member states that joined the EU in 2004 or later. ${ }^{3}$ The inclusion of this group of countries should add to our knowledge of welfare state regimes, as the new member states and their welfare models have been under-investigated in previous research on this topic. This approach will allow us to determine whether there is a distinct Central and Eastern European welfare regime model, or whether there are some similarities between the welfare states of the old and the new EU member states, as formulated in the first two research hypotheses.

The per capita public transfers, and, separately, the public consumption age profiles, are aggregated for three age groups: the young (0-19 years); the workingage (20-64 years), and the senior (65 years or older) generations. Using per capita age profiles, we examine the levels of public transfers paid and received, as well as the levels of public consumption, in an average representative of each age group. This approach allows us to avoid the population size bias in our analysis.

We use fixed age limits, but the NTA age profiles reflect country-specific characteristics that affect the public consumption and public transfer levels of these age groups. It should be noted that the age limits of economic dependency (that is, the ability to finance consumption from labour income) vary between countries, and that these limits are, in turn, outcomes of the differences between welfare regimes. This point has been discussed by, for example, Loichinger et al. (2017). In the analysis, the application of fixed age limits is needed to ensure the comparability of indicators.

The country-level assessment (section 3 ) is followed by the grouping of countries according to the similarities and differences in the levels of public consumption and of the transfers received and financed by different age groups (section 4). The conclusions from these two sections are used to verify the first three hypotheses.

With regard to the fourth hypothesis, the panel regression of public expenditures, with demographic dependency as the explanatory variable, is estimated to investigate whether in countries that belong to different clusters, public expenditure and ageing trends develop differently (section 5).

\section{Public consumption and transfers at different ages}

This section presents comparisons of public consumption and public transfer levels by age. First, we show the average age profiles of the levels and the structure of public consumption, as well as the public transfer levels for all EU 24 countries covered

\footnotetext{
3 These are: Austria, Belgium, Bulgaria, Cyprus, Czechia, Denmark, Estonia, Germany, Greece, Spain, Finland, France, Hungary, Ireland, Latvia, Lithuania, Luxembourg, Poland, Portugal, Romania, Slovakia, Slovenia, Sweden, and the United Kingdom. Due to the lack of data on public health consumption, Italy is excluded from the analysis.
} 
by the analysis. Then, we take a closer look at consumption and transfer patterns by age group for different countries. Finally, we analyse the distribution of selected public consumption and public transfer patterns in the three selected age groups.

The per capita age profiles of public transfers inflows (Figure 2(a)) show that individuals at younger ages and at older ages receive more public transfers than their working-age counterparts. These profiles include public consumption, which measures public in-kind services (Figure 2(c)-(e)) that tend to be equally directed to the young and the senior generations. Public transfer inflows are especially high for the senior age group. This means that cash transfers (particularly pensions) are mainly received by older people. The pattern for public transfer outflows per capita, shown in Figure 2(b), is rather different. These outflows are higher for those in the working-age generation, who tend to pay taxes, mainly on their labour income. It is worth noting that there is a large gap between the minimum and the maximum per capita public transfer outflows for the older age groups, which reflects the different national approaches to taxing social transfers. The net transfers are higher for those in the older age group, who receive large public transfer inflows, particularly in the form of pensions and health care consumption. At the same time, older people have lower public transfer outflows.

At the country level, there are differences in the total level of per capita public transfers (Figure 3). The aggregated per capita public transfer inflows for all ages are highest, exceeding 40 annual labour incomes, in the 30-49 age group in Luxembourg. They are lowest (less than 28 annual wages) in Romania, Slovenia, Bulgaria, and Germany. It should be noted that these are relative values, which helps to explain the comparatively low position of Germany, where the average income of prime-age workers is high. Together with public finance reforms introduced in Germany in the past decade, this may account for the (relatively) low level of public transfer inflows, including of public consumption, in that country.

\section{Public consumption and transfers by age groups}

The per capita public consumption aggregated by age groups differs across countries. Table 1 presents a summary of public consumption by type of consumption and selected age group.

For the young age group and the working-age group, the largest (relative) spread, measured as the ratio between the maximum and the minimum consumption levels, is for public education consumption. The country with the lowest public education consumption level for people in the 20-64 age group (the United Kingdom) spends seven times less on public education than the country with the highest consumption level (Sweden). In the senior age group, the ratio between the maximum and the minimum observed public transfer levels is the highest for public health consumption, and is twice as high as it is for the rest of public consumption.

Figure 4 shows the aggregated per capita public consumption, public transfers inflows, and public transfers outflows for each age group. The overall public consumption level (Figure 4(a)) is highest for the working-age group, which covers the largest number of single age cohorts (45). However, in Cyprus, Austria, and 
Figure 2:

Average age profiles of per capita public consumption and public transfers in $24 \mathrm{EU}$ countries

a. Public transfers per capita - inflows

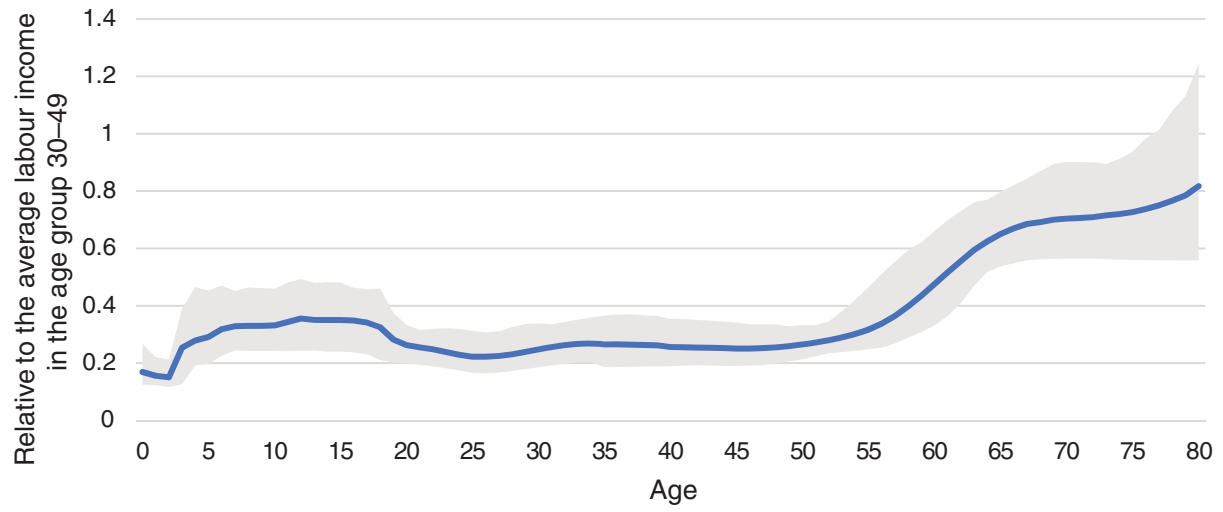

b. Public transfers per capita - outflows

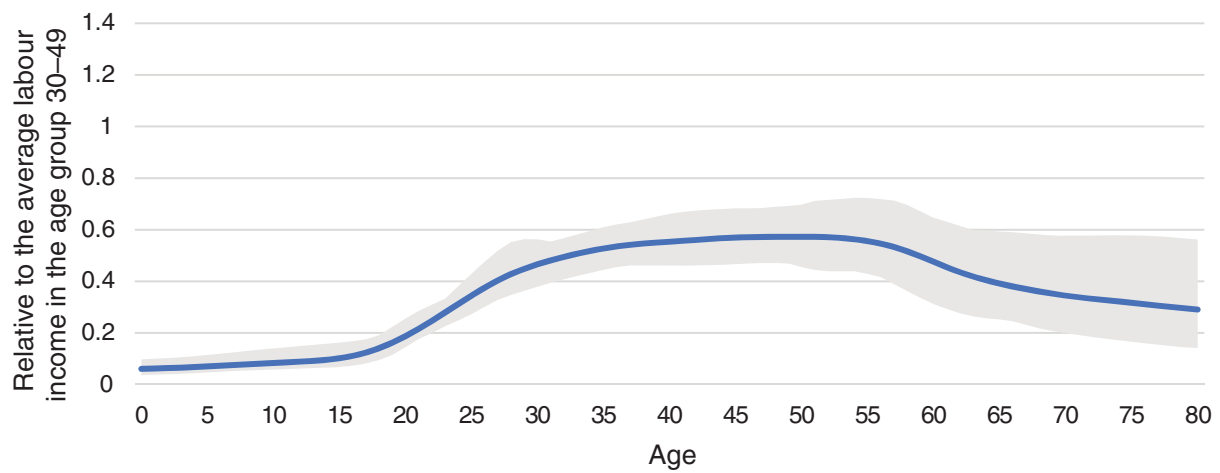

c. Public consumption per capita - education

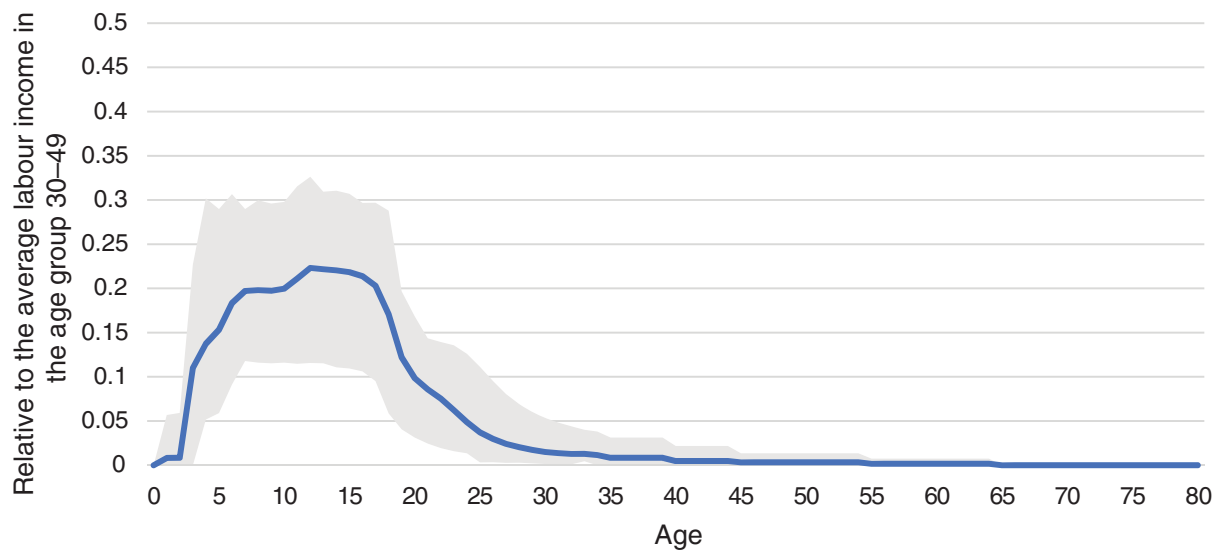

Continued 
Figure 2:

\section{Continued}

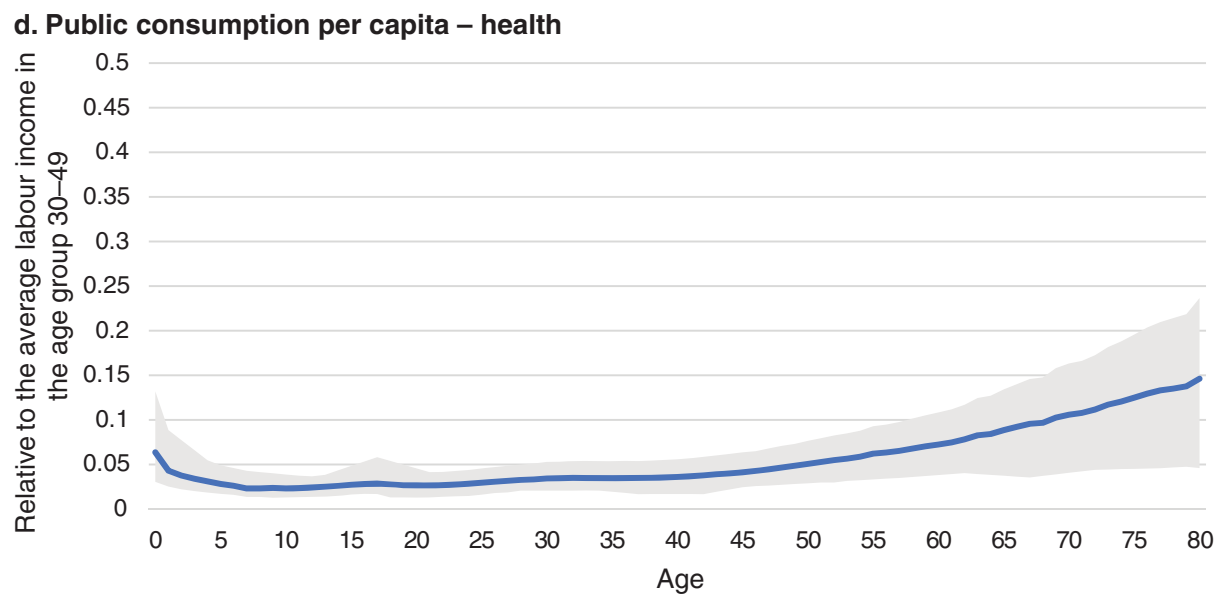

e. Total public consumption per capita (EU-24 average)

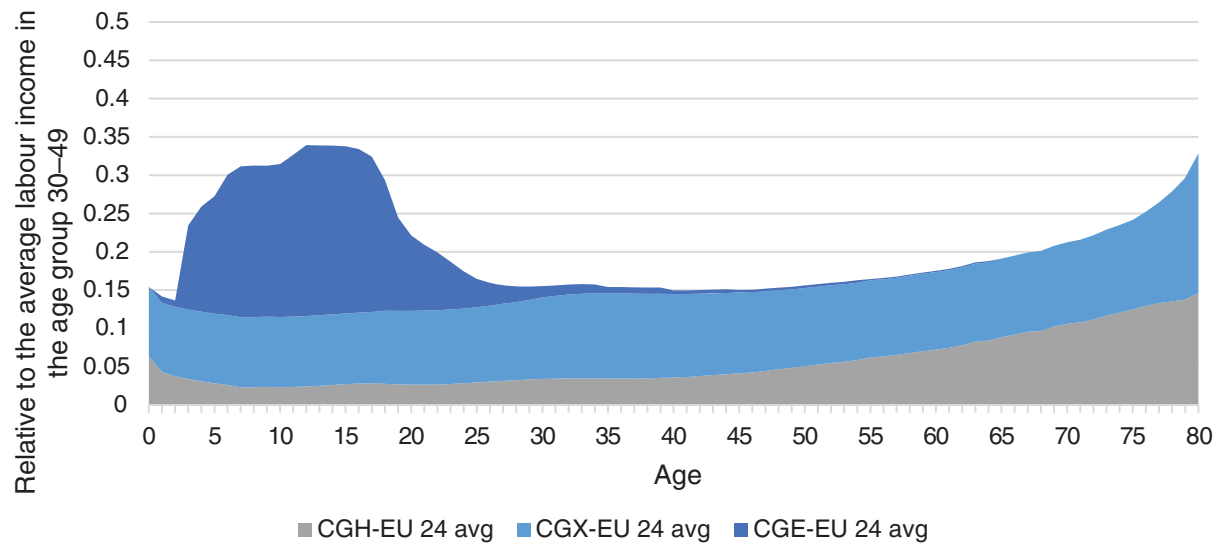

Note: (1) The areas in Figures 2(a)-2(d) show the minimum and the maximum per capita values across the 24 countries, and the lines depict the EU-24 average.

(2) CGE - public consumption of education, CGH - public consumption of health, CGX - other public consumption.

Source: Authors' estimations based on Istenič et al. (2017), European National Transfer Accounts. Available at: http://www.wittgensteincentre.org/ntadata.

Latvia the public consumption level of the young age group (20 cohorts) is similar to that of the working-age group. By contrast, in Finland, Sweden, Ireland, the UK, Germany, and Romania, the public consumption level of the young age group is close to that of the senior age group ( 15 cohorts between ages 65 and 80).

The total public transfer inflows (Figure 4(b)) also differs between age groups. Of the age groups, the senior age group receives the largest amount of transfers 
Figure 3:

The total level of per capita public consumption in the $24 \mathrm{EU}$ countries (summed for ages 0-80)

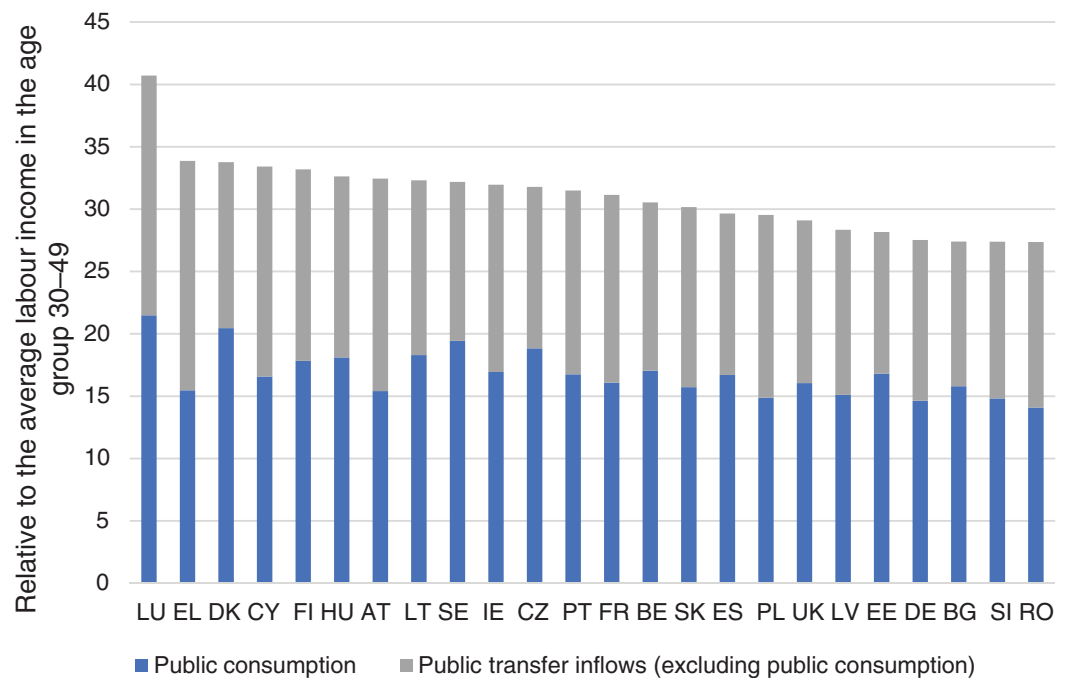

Source: Authors' estimation based on Istenič et al. (2017), European National Transfer Accounts. Available at: http://www.wittgensteincentre.org/ntadata.

Table 1:

Public consumption by type of expenditure and age group in the EU-24 (expressed in relation to average annual earnings for 30-49-year-old workers)

\begin{tabular}{|c|c|c|c|c|c|c|c|c|}
\hline & \multicolumn{3}{|c|}{ Young (0-19) } & \multicolumn{3}{|c|}{ Working-age (20-64) } & \multicolumn{2}{|c|}{ Senior $(65-80)$} \\
\hline & CGE & CGH & CGX & CGE & CGH & CGX & CGH & CGX \\
\hline EU-25 country average & 3.23 & 0.60 & 1.84 & 0.67 & 2.07 & 4.65 & 1.86 & 1.92 \\
\hline Min & 1.74 & 0.37 & 1.28 & 0.25 & 1.22 & 3.48 & 0.68 & 1.33 \\
\hline Max & 4.82 & 0.86 & 2.41 & 1.76 & 3.11 & 6.14 & 2.88 & 2.88 \\
\hline $\max / \min$ & 2.77 & 2.34 & 1.89 & 7.00 & 2.56 & 1.77 & 4.25 & 2.17 \\
\hline
\end{tabular}

Notes: (1) CGE - public consumption, education, CGH - public consumption, health, CGX - public consumption, other

(2) The public consumption of each age group is measured as a sum of per capita values for one-year age groups included in the respective age group.

Source: Authors' estimation based on Istenič et al. (2017), European National Transfer Accounts. Available at: http://www.wittgensteincentre.org/ntadata.

in Luxembourg, Greece, Denmark, and Austria. Moreover, in the UK, the transfer amounts received by the senior age group even exceed these of the working-age group, and are similar those in Greece, Austria, and Germany. On the other hand, in Latvia and Estonia, the transfer inflows for the senior age group are lower, and are 
Figure 4:

Public consumption, public transfer inflows, and outflows by age groups, aggregated by age per capita relative values

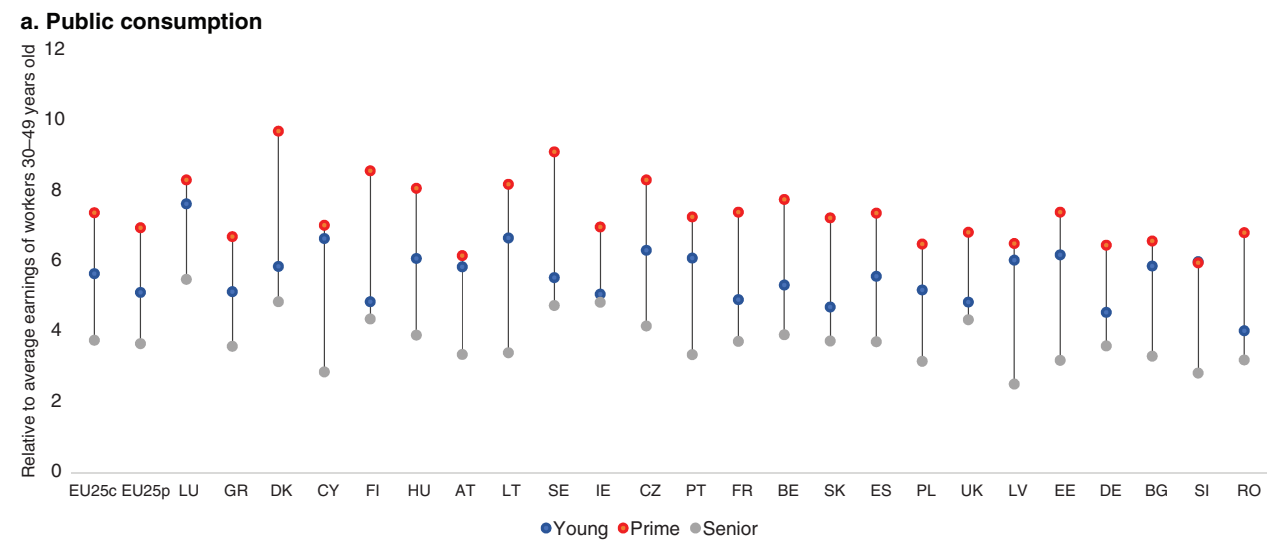

b. Public transfer inflows

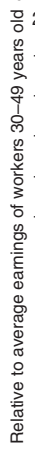

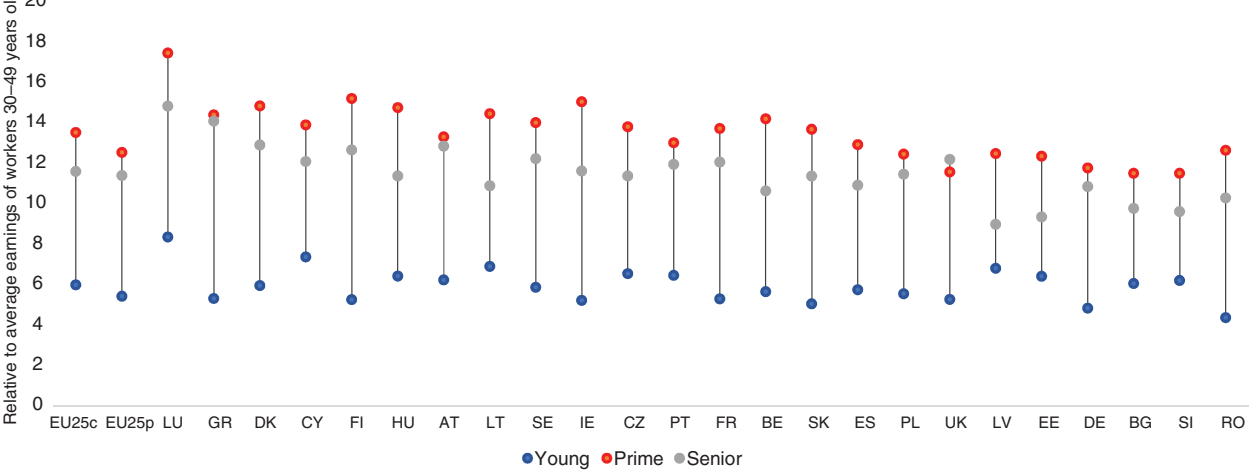

c. Public transfer outflows
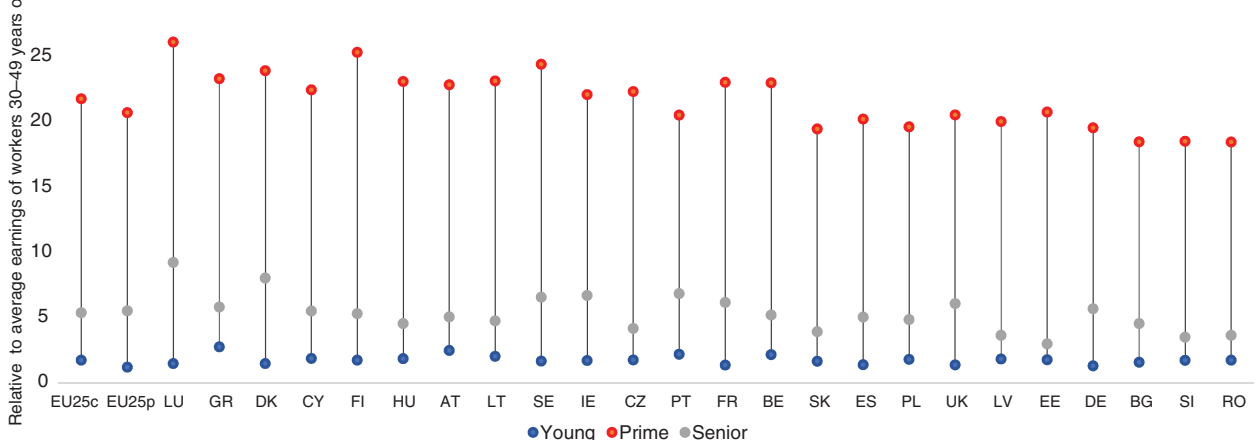

Source: Authors' estimation based on Istenič et al. (2017), European National Transfer Accounts. Available at: http://www.wittgensteincentre.org/ntadata. 
much closer to those for the young age group. Not surprisingly, we see that across countries, the age distribution of public transfer outflows is very similar, with the largest amounts paid by those in the working-age group (Figure 4(c)). The public transfer outflow levels are lowest in Romania, Bulgaria, and Slovenia; while they are highest in Luxembourg, Finland, and Denmark.

\section{Age distribution of public spending and consumption}

The age distribution of public consumption and public transfers in the countries is summarised in the form of ternary graphs in Figure 5. The figures show average per capita public transfer inflows and outflows, and public consumption per one cohort in the analysed age groups.

The public services for education and health have a clear age bias. As public consumption of education (Figure 5(a)) is concentrated in the young age group corner, and is distributed between the working-age group and the young age group, public education consumption is spread along the young-prime age group axes. Public consumption of health (Figure 5(b)) is more concentrated in the senior age group. There is also a slight bias towards the senior age group for public transfer inflows (Figure 5(c)). Public transfer outflows (Figure 5(d)) are mainly funded by the working-age group, and to some extent by the senior age group. The young age group is barely involved in financing public transfer outflows.

\section{Are public transfers for different age groups welfare regime-specific?}

The differences and the similarities in the total levels of public transfers and public consumption, and in their age distributions, can be seen as the outcomes of existing welfare policies. In this section, we present the results of the cluster analysis that aims to determine whether the types of welfare regimes proposed by EspingAndersen $(1990,1999)$ are also reflected in the outcomes of these policies with respect to public consumption and transfer levels by age groups, as observed in 2010.

In order to select the groups of countries, we performed a cluster analysis, which is an exploratory statistical technique applied to distinct groups of observations (in our case, countries) with a high degree of intra-class similarity and a low degree of inter-class similarity.

We start the analysis by including all variables for all age groups. In the first step, we used the Kaiser-Meyer-Olkin (KMO) measure of sampling adequacy to select the variables for the model. ${ }^{4}$ Based on this test, the following variables were

\footnotetext{
4 The KMO test measures sampling adequacy for each variable in the model and for the complete model. The statistic is a measure of the proportion of variance among variables that might be common variance.
} 
Figure 5:

Public and private consumption of education and health, and other consumption in selected EU countries by age groups

a. Public consumption education

0-19

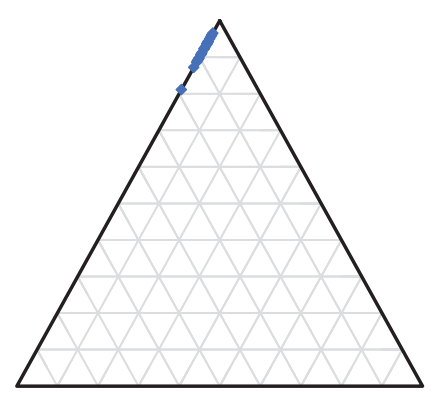

20-64

c. Public transfers, inflows

0-19

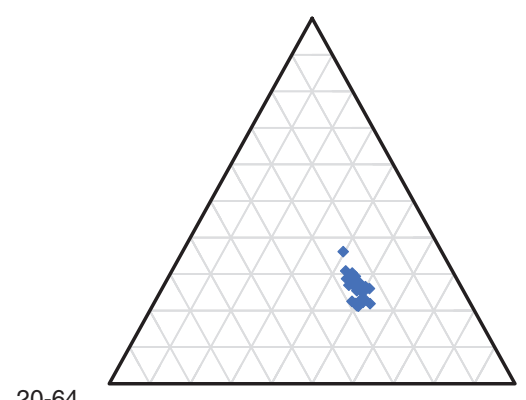

b. Public consumption health

0-19

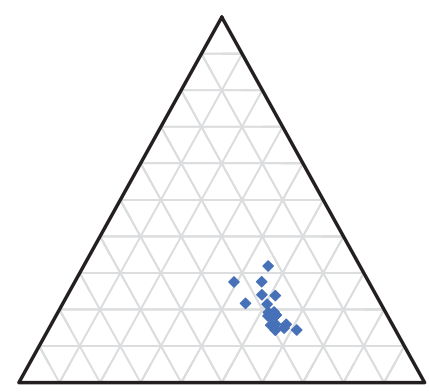

$65+$

d. Public transfers, outflows

0-19

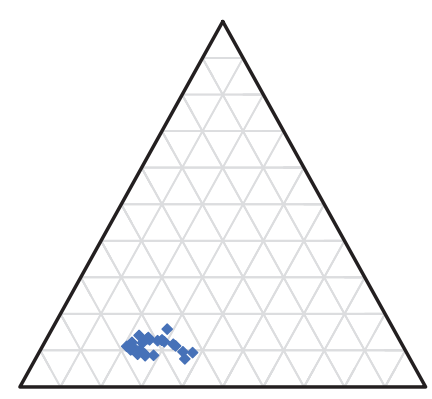

$65+\quad 20-64$

$65+$

Note: The blue points represent countries. The closer the points are to the selected corners of the triangle; the more the consumption or the transfer is oriented towards the age group assigned to the corner.

Source: Authors' estimation based on Istenič et al. (2017), European National Transfer Accounts. Available at: http://www.wittgensteincentre.org/ntadata.

included in the analysis:

- public consumption of health for people in the age group 65+ (CGH 65+),

- other public consumption for people in the age group 65+ (CGX 65+),

- total public inflows for people in the age group 20-64 (TGI 20-64),

- total public inflows for people in the age group 65+ (TGI 65+),

- total public outflows for people in the age group 20-64 (TGO 20-64),

- total public outflows for people in the age group 65+ (TGO 65+). 
The remaining variables were excluded from the analysis because the low value of the KMO indicated that there was too much common variance between variables. ${ }^{5}$ For the first five variables, the KMO level exceeds 0.8; and for the last variable, it is close to that level. For the entire model, the KMO level is equal to 0.81, which indicates that the sampling is adequate.

To select the country groups, we applied the principal component analysis (PCA), which enabled us to reduce the number of variables. ${ }^{6}$ We then conducted a hierarchical cluster analysis using components that were established in the PCA.

In the analysis, three groups of countries emerged:

- Cluster 1-European, in which the age profiles of public transfers are close to the EU average. This cluster is comprised of both liberal and continental welfare regimes that seem to exhibit similar age patterns for public transfers, including for levels of public consumption. This cluster is the largest of the three, and includes 14 countries: Austria, Belgium, Cyprus, Czechia, Germany, Greece, Spain, France, Hungary, Ireland, Lithuania, Poland, Portugal, Slovakia, and the United Kingdom.

- Cluster 2-Underdeveloped, which is characterised by below-average transfers by age. This cluster is made up of five new member states: Bulgaria, Estonia, Latvia, Romania, and Slovenia.

- Cluster 3-Scandinavian, which is characterised by above-average public transfer and consumption levels by age. This cluster is comprised four countries, including three Nordic social democratic states: Denmark, Finland, Sweden, and Luxembourg.

The clusters are distinct with regard to their public transfer and public consumption patterns, as Figures 6 and 7 make clear. The average public transfer amounts (both inflows and outflows) in the largest cluster 1 (European) are close to the all-country average (Figure 6), which is partially because it is the largest group of countries. The countries in cluster 2 (underdeveloped) have both lower public inflow levels, particularly for the 60+ age group, and lower outflow levels for the 30+ age group. The countries in cluster 3, which include the Scandinavian countries, have higher outflows for the same age group. The public inflows in this cluster are higher for both the older age group and the prime-age group.

The situation for public consumption (Figure 7) is similar. Countries in cluster 1 are at the European average. The countries in cluster 2 have lower public consumption levels, particularly of health. The countries in cluster 3 have higher public health consumption levels for the older age groups. The pattern of public education consumption in the cluster 3 countries is distinct: i.e. levels of public

\footnotetext{
5 These are: public education consumption (CGE 0-19, CGE 20-64), public health consumption (CGH 0-19, CGH 20-64), other public consumption (CGX 0-19, CGX 20-64), and public transfers inflows and outflows for the young age group (TGI 0-19, TGO 0-19).

6 The PCA results show that the first two components explain more than $80 \%$ of the observed variance.
} 
Figure 6:

Public transfers by clusters

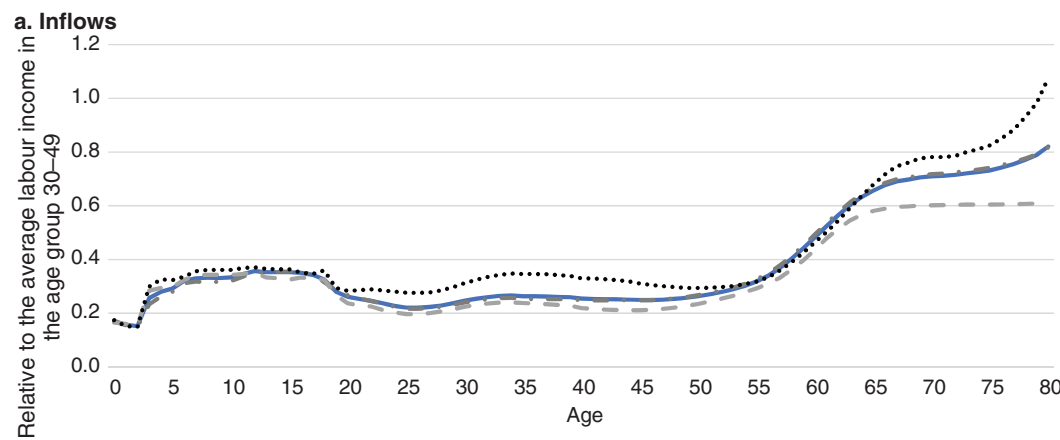

_EU 25 - .. European - - Underdeveloped ...... Scandinavian

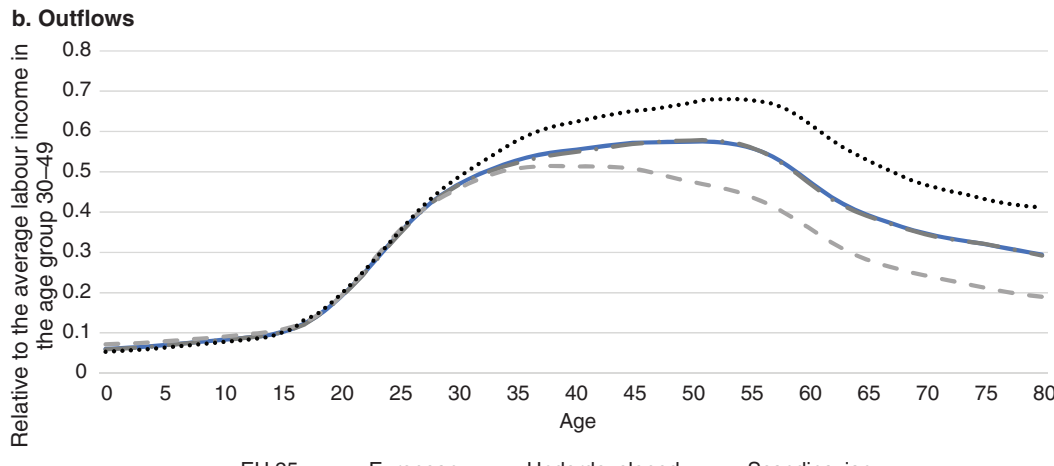

_EU 25 _. European - - Underdeveloped ...... Scandinavian

Source: Authors' estimation based on Istenič et al. (2017), European National Transfer Accounts. Available at: http://www.wittgensteincentre.org/ntadata.

education consumption are higher for children in pre-school education and for adults aged 20 to 40 .

The observed age profiles of public consumption and transfers averaged for the three groups of countries show that there are important differences in the allocation of per capita transfers across age groups, and that the senior generation is especially distinct. These patterns confirm the existence of different welfare state regimes in Europe, albeit with a different composition than the one initially presented by Esping-Andersen. This new clustering of welfare regimes provides empirical evidence in support of the first hypothesis, which states that countries with a social democratic regime (i.e. with a developed welfare state) have high public transfer levels directed at all age groups. Similarly, in support of the second hypothesis, which states that the majority of Eastern European countries are still developing their welfare regimes, and thus have relatively low public transfer and public 
Figure 7:

Public consumption by clusters

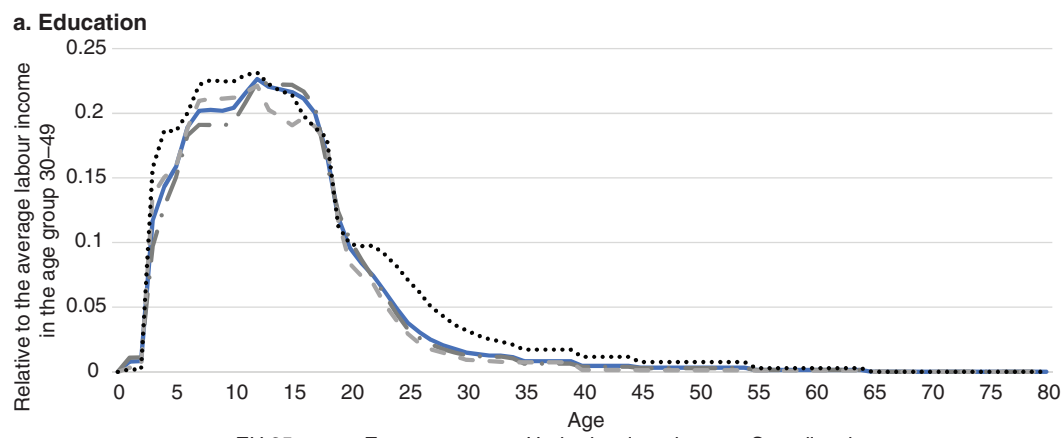

_EU 25 —. European - - Underdeveloped ...... Scandinavian

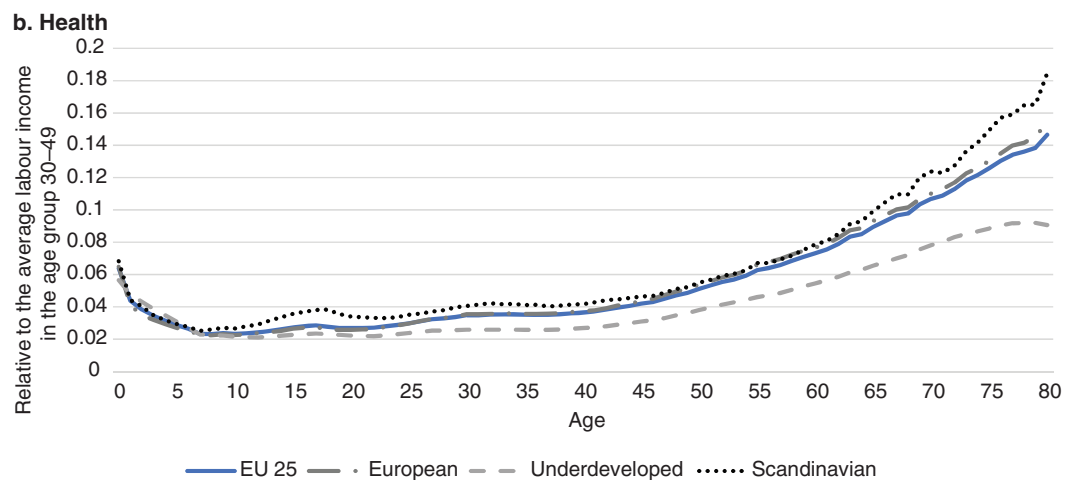

Source: Authors' estimation based on Istenič et al. (2017), European National Transfer Accounts. Available at: http://www.wittgensteincentre.org/ntadata.

consumption levels, the analysis showed that five of the new member states can be assigned to cluster 2 , which is comprised of underdeveloped welfare regimes.

Last but not least, the large number of countries assigned to cluster 1 supports the third hypothesis: namely, that the welfare models of liberal and continental countries are converging with regard to the age distribution of public transfers, including of public consumption.

Summing up, we find that the evolution of welfare states - particularly after the turn of the century and the onset of the financial crisis - has led to some, but not full convergence in the direction and the scale of public transfers by age. The most important differences are observed in the senior age groups, and are particularly large between older people in Scandinavian countries and in Central and Eastern European countries. This finding implies that as the population ages and the share of older cohorts in the total population increases, these differences will translate into different pressures on additional increases in public transfers. In the next section, we investigate whether the first signs of such pressures are already being observed. 


\section{Demographic change, welfare regimes, and public expenditures}

Following the cluster analysis, our aim in this section is to verify whether the clusters of countries differ in terms of the age structures of their populations, and in terms of their public expenditures (including their social protection expenditures) and revenues in the last two decades (between 1995 and 2014).

As Figure 8 shows, the three groups (clusters) of countries have different population age structures, as measured by the total support ratio (TSR), which indicates the number of people in the 20-64 age group per 100 people below or above these age limits. A declining TSR might result from more advanced population ageing and a shrinking working-age population.

Overall, in the countries in cluster 1 and cluster 2, the TSR was increasing between 1995 and 2008, which means that the demographic structures in these groups of countries still provided conditions that enabled financing transfers to the young and to the senior generations. There are, however, some differences between these two clusters that can be pointed out. The countries in cluster 2 have a higher TSR than the countries in cluster 1. This is because the Central and Eastern countries had higher fertility than the developed countries in the 1970s and 1980s, which resulted in large inflows of young people to the working-age generation in the 1990s and at the beginning of the century. After 2010, the TSR started to decline in both clusters, largely because the inflows of people to working ages were lower, and the outflows of people to working ages were higher, as members of the post-war baby boom generation started to reach age 65 .

The decline in the TSR in cluster 3 is observed from the beginning of the $21 \mathrm{st}$ century, with the share of people aged 65+ in the population increasing, and the share of young people in the population remaining relatively stable. As the share of children in the population is high in this group of countries, the TSR is lower than it is in the two other clusters.

From 2010 onwards, the TSR declines in all groups of countries, mostly due to advances in population ageing.

The central government expenditure (CGE) patterns differ between the three groups (Figure 9). The countries in cluster 2 have a relatively low ratio of expenditures to GDP, and with a slightly increasing trend on average. After the onset of the crisis in 2008, public expenditure levels rose in all three clusters, primarily as a result of declining GDP and increasing public spending in response to needs caused by the crisis and post-crisis policies. However, since 2010, public expenditures have declined to almost pre-crisis levels in the cluster 1 countries. In contrast, in the cluster 3 countries, central government expenditures have remained at higher levels since the financial crisis.

The clusters also differ with respect to central government revenue (CGR) levels, which are shown in Figure 10. The average CGR level in cluster 3 is 10 p.p. higher than it is in cluster 1, and is almost 15 p.p. higher than it is in cluster 2. The CGR level remains relatively stable over time. 
Figure 8:

Total support ratio by clusters

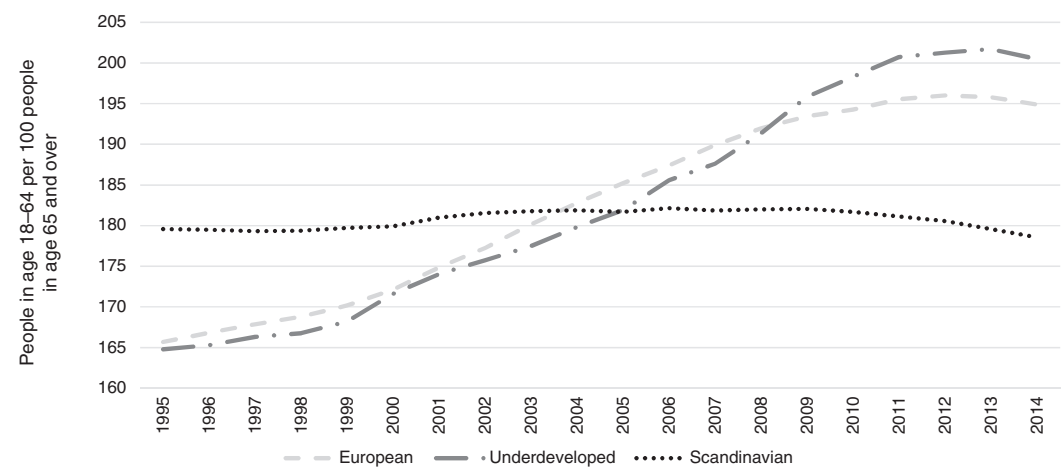

Source: Authors' analysis based on the EUROSTAT data.

Figure 9:

Central government expenditures by clusters (\% GDP)

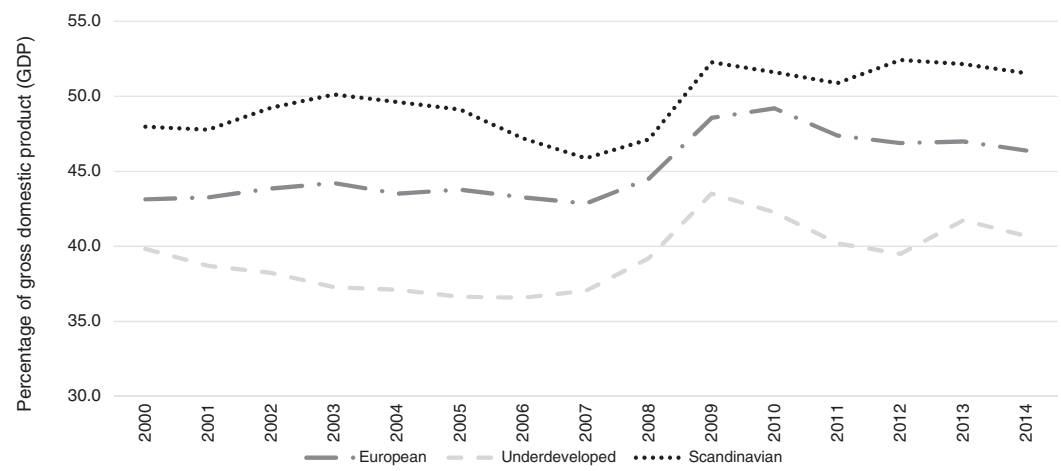

Source: Authors' analysis based on the EUROSTAT data.

The three groups of countries also differ in terms of social protection expenditure (Figure 11) levels, which are lowest in the cluster 2 countries and are highest in the cluster 3 countries. The level of social protection spending relative to GDP increased after the crisis, and has since remained stable in all three clusters. The difference between cluster 2 and cluster 3 in the average of the social protection expenditures amounts to 7 p.p. of GDP. This means that around two-thirds of the difference in the overall level of public expenditures is due to differences in social expenditure levels. 
Figure 10:

Central government revenues by clusters (\% GDP)

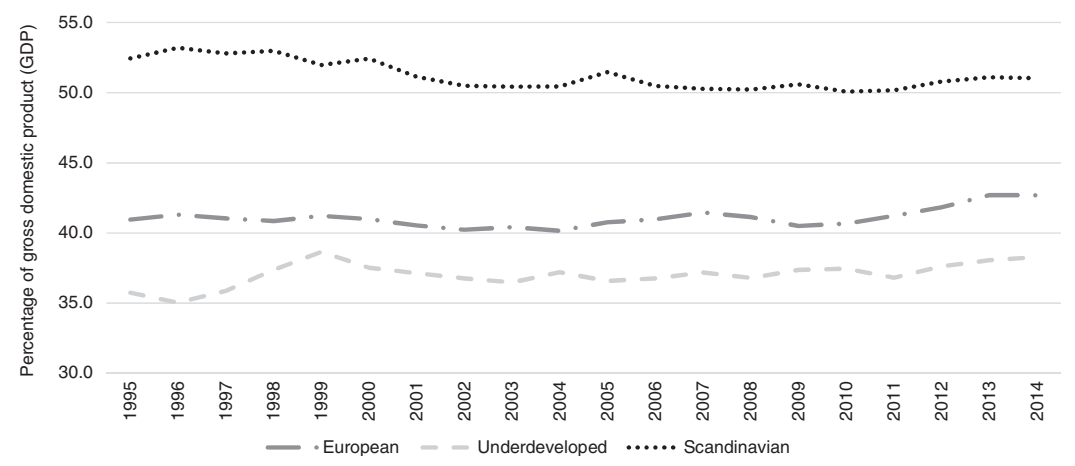

Source: Authors' analysis based on the EUROSTAT data.

Figure 11:

Social protection expenditures by clusters (\% GDP)

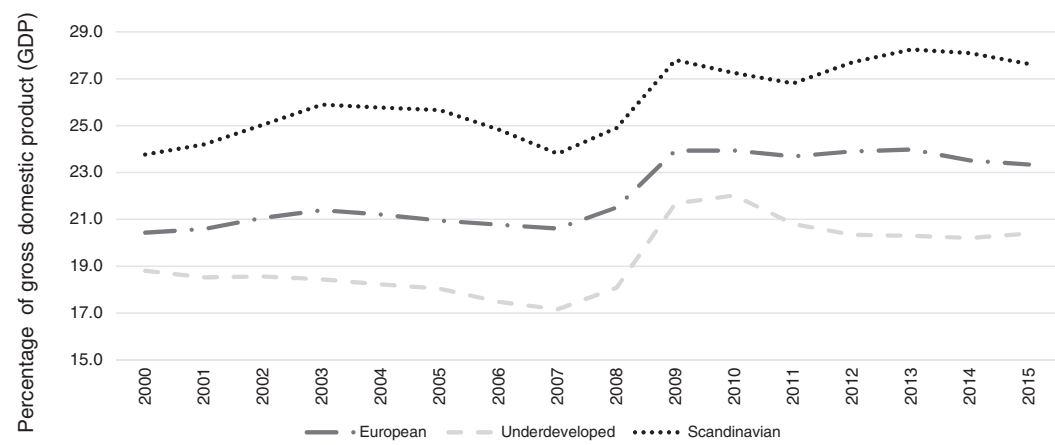

Source: Authors' analysis based on the EUROSTAT data.

Summing up, our analyses provide arguments consistent with the third hypothesis regarding cluster-specific developments in public expenditures and revenues, and in social protection spending, in the past two decades.

\section{Welfare regimes and public expenditures in response to ageing}

Finally, in seeking to answer the question of whether changes in public finances in response to demographic developments differ between the proposed groups 
(clusters) of countries, we use the panel regression models with the variables introduced in the previous sections. The analysis is performed for the total sample of 24 countries, and then separately for each cluster. We apply the standard random effects panel regression, whereby the observations of the dependent variable $y_{i t}$ for each country $i$ and time $t$ are described by the observations of the explanatory variable $x_{i t}$ in the linear regression model, defined in equation (2) as follows:

$$
y_{i t}=\mu+x_{i t}^{\prime} \beta+u_{i t}, \quad \text { where } u_{i t}=\alpha_{i}+\varepsilon_{i t} .
$$

The error term $u_{i t}$ in the panel regression model contains effects specific to the countries $\alpha_{i}$ and the pure error term $\varepsilon_{i t}$.

In the panel regression below, there are three possible dependent variables $y_{i t}$ : central government expenditure (CGE), central government revenue (CGR), and social protection expenditure (SPE). We considered in all cases the same explanatory variable $x_{i t}$; that is, the change in the total support ratio (TSR).

The first model, based on the full sample of 24 European countries $(i=1, \ldots, 24)$, shows that in the past two decades (between 1995 and 2014), there was no consistent and significant relationship between the TSR and the public revenue and the expenditure variables (Table 2).

The coefficients are not significant for the regressions with the full sample of countries if the robust method of estimation parameters is applied.

Some significant results for variables CGR and SPE are obtained in the models for the selected clusters of countries introduced in section 3 . This suggests that the reactions of public finances to the demographic changes measured by TSR are more homogenous within clusters. In the "European" cluster 1 (15 countries), the panel regression does not find a significant association of the dependent variables with population ageing.

In the "underdeveloped" cluster 2 (Bulgaria, Estonia, Latvia, Romania, Slovenia), the regression coefficient is positive both for the revenue variable (CGR) and the social expenditure variable (SPE). This means that as the population ages (and the TSR decreases), central government revenues and public social expenditures are also declining. Decreases in central government revenues can indicate that the stability of public finances is at risk. On the other hand, these countries have managed to reduce the ratio of social expenditures to GDP, which suggests that they are able to stabilise the situation.

In the "Scandinavian" cluster 3 (Denmark, Finland, Sweden, Luxembourg) the regression coefficient for central government revenues is negative, which means that as the population ages, central government revenues are, on average, increasing. This could be the result of the policies implemented in these countries aimed at extending working life (for example, increasing the retirement age). The negative (though not significant) regression coefficient for public expenditures and social protection expenditures illustrates that public spending is increasing as the population ages. Taken together, these results indicate that the current trends related to population ageing are leading countries to make adjustments, like reduced transfers 


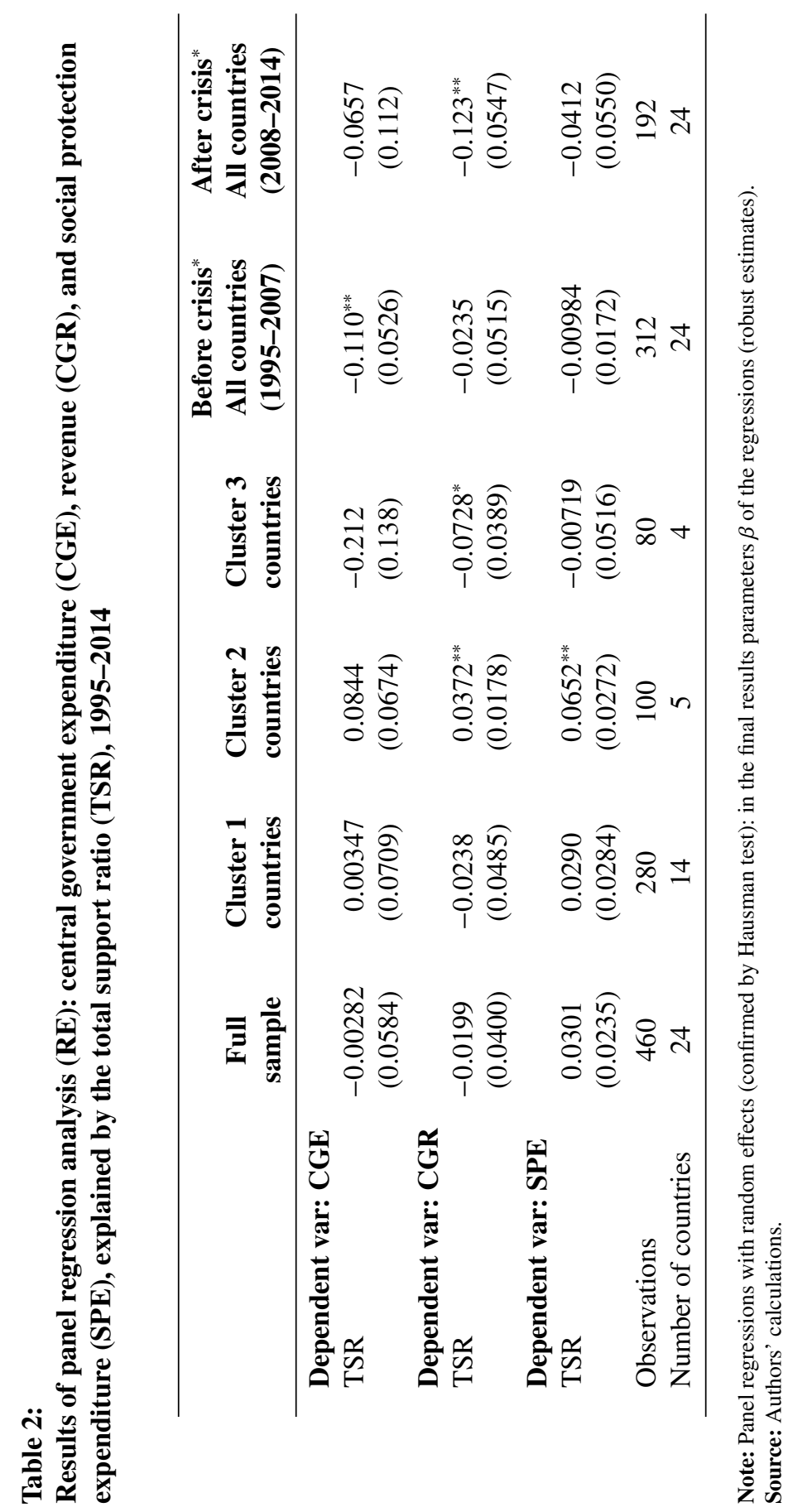


in cluster 2 countries and increased transfers in cluster 3. If these trends continue, the further divergence of the welfare systems can be expected.

Another source of the shift in the relationship between the total support ratio and public policies is the change in conditions before and after the onset of the financial crisis in 2008. In this analysis, two panel regressions are considered: first, for all countries and for the 1995-2007 period; and, second, for all countries and for the 2008-2014 period. In the pre-crisis sample, there is a significant negative regression coefficient for the total support ratio in the model of central government expenditures, and an insignificant regression coefficient in the model of revenues. This could mean that the pressure created by demographic change led to increasing expenditures, but did not necessarily affect the revenue side in the pre-crisis period, when there were relatively easy opportunities to increase the public debt.

For the period after the crisis, the panel regression results suggest that the pressure to increase central government revenues grew despite the ageing of the population. This may have been an effect of austerity measures, which halted the expansion of public expenditures and put pressure on the revenue side at at a time when there were fewer opportunities to react to demographic changes by increasing public debt.

\section{Conclusions}

The application of the NTA age profiles allowed us to examine the outcomes of socioeconomic policies, measured by the public consumption and transfer levels of different age groups, which account for the distribution of consumption of education, health, and other public goods. All European countries direct a significant share of public consumption to the young and the senior age groups. However, the distribution of public consumption by age differs significantly between countries.

We identified three clusters of countries that have different patterns of public transfers to the young and the senior age groups, and of taxes levied on the workingage group.

These are countries with:

(i) close to average levels of public transfers and public consumption for all age groups (15 countries representing all of the welfare regime types, according to the Esping-Andersen typology);

(ii) low public transfer and public consumption levels (five Central and Eastern European countries); and

(iii) higher public transfer levels directed at all age groups, and especially at older people, and higher public expenditures (Luxembourg and three Scandinavian countries).

The results of the clustering show that the countries with conservative and liberal regimes, according to the Esping-Andersen typology, together with several new member states, converged to show similar patterns for the age distribution of public transfers and consumption. The social democratic countries remain a distinct group, 
with more generous transfers to people of all ages, but with a focus on the older group. Finally, some of the new member states in Eastern and Southern Europe form a cluster of underdeveloped welfare regimes with lower levels of public consumption and transfers, including of public health consumption, for older people in particular. These findings confirm the first and the second hypotheses.

Our results indicate that the outcomes of different types of welfare regimes lead to similar outcomes with regard to the average age profiles of public transfers and public consumption. This means that there has been a convergence of transfers to selected age groups in the continental and the liberal welfare regimes, which confirms our third hypothesis. This development may be attributable to social reforms and austerity measures introduced in reaction to the 2008 economic crisis, which led to reductions in public expenditures and public transfers inflows (benefits). Our analysis does not take into account the distribution within age groups (i.e. from higher-income groups to lower-income groups), which may be distinct between the countries.

In countries with different welfare regimes, the development of public expenditures in general and of social protection expenditures in particular has also differed. The countries with higher age-related public transfers have tended to increase their public revenues and expenditures in recent years in response to changing population age structures, which has, in turn, reduced the effects of the total support ratio. On the other hand, the group of countries that have lower per capita public age transfers and public consumption levels seem to have reduced their general government revenues and expenditures, including their social protection expenditures. This may point to a further divergence in public transfer and consumption levels by age in the $\mathrm{EU}$, with progressive changes occurring in the population age structures of the two groups of countries that have different public transfer levels for different age groups. This observation confirms our fourth hypothesis.

Our NTA-based study on links between public finances (central government expenditures and central government revenues) and the ageing of the population from a comparative perspective ( $24 \mathrm{EU}$ countries) extends research on the economic consequences of ageing in several ways. First, we have taken into account the economic flows related to consumption and labour income that are driven by socioeconomic developments, as well as by the existing welfare systems in Europe. Second, we have applied new approaches to depicting past developments in ageing and economic flows. These approaches have allowed us to assess the outcomes of welfare policies through the age distribution of public transfers. The research results presented in this article indicate the importance of analysing the age distribution of public transfers. These transfers are also complemented by private transfers within and between households, as well as by asset-based reallocations and savings. Therefore, we propose using an approach in future research that includes private transfers and individual funding when analysing the financing of consumption at young and senior ages. Such an approach could bring greater nuance to the question of how each country deals with population ageing, and could uncover differences between the countries in the largest, European cluster. 


\section{Acknowledgements}

The research for this article was supported by AGENTA project, funded from the European Union's Seventh Framework Programme for research, technological development and demonstration under grant agreement no 613247 and the national funding for science in the years 2014-2017, granted for the implementation of the co-financed international project. The authors would like to thank the reviewers for their insightful comments on the earlier version of the article, and the participants of the AGENTA final conference, particularly Bernhard Hammer, for their comments and suggestions.

\section{References}

Arcanjo M. 2006. Ideal (and real) types of welfare state. Working Papers, Department of Economics 2006/06, ISEG - Lisbon School of Economics and Management, Department of Economics, Universidade de Lisboa.

Arcanjo, M. 2011. Welfare state regimes and reforms: A classification of ten European countries between 1990 and 2006. Social Policy and Society 10(2): 139-150.

Arts, W. and J. Gelissen 2002. Three worlds of welfare captialism or more? A state-of-the-art report. Journal of European Social Policy 12(2): 137-158.

Cerami, A. and P. Vanhuysse 2009. Post-communist welfare pathways: Theorizing social policy transformation in central and Eastern Europe. Basingstoke: Palgrave.

Chauvel, L. and M. Schroder 2014. Generational inequalities and welfare regimes. Social Forces 92(4): 1259-1283. DOI: 10.1093/sf/sot156.

Daly M. and J. Lewis 2000. The concept of social care and the analysis of contemporary welfare states. British Journal of Sociology 51(2): 281-298.

Esping-Andersen, G. 1990. The three worlds of welfare capitalism. Princeton University Press.

Esping-Andersen, G. 1999. Social foundations of postindustrial economies. Oxford University Press.

Esping-Andersen, G. and J. Myles 2009. Economic inequality and the welfare state. In The Oxford handbook of economic inequality, eds B. Nolan, W. Salverda and T. M. Smeeding, 639-664, Oxford: Oxford University Press.

Fenger, H. 2007. Welfare regimes in central and Eastern Europe: Incorporating postcommunist countries in a welfare regime typology. Contemporary Issues and Ideas in Social Sciences (August): 3-30.

Ferrara, M. 1997. The southern model of welfare in social Europe. Journal of European Social Policy 6(1): 17-37.

Gál, R. I. and M. Medgyesi 2017. Financing the lifecycle or mitigating poverty: Redistribution in the Hungarian welfare system by age and income (NTA Working Paper No. 20).

Istenič, T., B. Hammer, A. Šeme, A. Lotrič Dolinar and J. Sambt 2017. European National Transfer Accounts.

Kammer, A., J. Niehues and A. Peichl 2012. Welfare regimes and welfare state outcomes in Europe. Journal of European Social Policy 22(5): 455-471. DOI: $10.1177 / 0958928712456572$. 
Korpi, W. and J. Palme 1998. The paradox of redistribution and strategies of equality: Welfare state institutions, inequality and poverty in the Western countries. American Sociological Review 63: 661-687.

Lee, R. D. 2013. Intergenerational transfers, the biological life cycle, and human society. Population and Development Review 8: 23-35. Retrieved from http://onlinelibrary.wiley. com/doi/10.1111/j.1728-4457.2013.00549.x/abstract.

Lee, R. D. and A. Mason 2011a. Generational economics in a changing world. Population and Development Review 37(SUPPL. 1): 115-142. DOI: 10.1111/j.1728-4457.2011.00380.x.

Lee, R. D. and A. Mason 2011b. Population aging and the generational economy: A global perspective. Edward Elgar Publishing Limited.

Leira, A. 2002. Working parents and the welfare state. Family Change and Policy Reform in Scandinavia, Cambridge University Press.

Lewis J. and I. Ostner 1994. Gender and the Evolution of European Social Policies, University of Bremen, Centre for Social Policy Research, ZeS-Working paper No 4/94.

Loichinger, E., B. Hammer, A. Prskawetz, M. Freiberger and J. Sambt 2017. Quantifying economic dependency. European Journal of Population 33(3): 351-380. DOI: $10.1007 / \mathrm{s} 10680-016-9405-1$.

Powell, M. and A. Barrientos 2004. Welfare regimes and the welfare mix. European Journal of Political Research 43(1): 83-105. DOI: 10.1111/j.1475-6765.2004.00146.x.

Saraceno, C. and W. Keck 2010. Can we identify intergenerational policy regimes in Europe? European Societies 12(5): 675-696. DOI: 10.1080/14616696.2010.483006.

Schut, J. W., Vrooman, J. and P. de Beer 2001. On worlds of welfare: Institutions and their effects on eleven welfare states. The Hague: Social and Cultural Planning Office of the Netherlands.

Stoy, V. 2014. Worlds of welfare services: From discovery to exploration. Social Policy and Administration 48(3): 343-360. DOI: 10.1111/spol.12006.

UN 2013. National Transfer Accounts manual: Measuring and analysing the generational economy. New York: United Nations Department of Economic and Social Affairs, Population Division. 